\title{
Investigation of mechanical properties of bamboo/ sisal fiber reinforced hybrid composite materials
}

\begin{abstract}
Sisal and Bamboo fibers are the most common fibers extracted from natural plants used to fabricate the bio-composite, environmentally friendly products. In this work, the BambooSisal fibers reinforced epoxy hybrid composite is fabricated to investigate and analyze the compression and hardness properties. The fibers were extracted mechanically and manually from bamboo and sisal plants. The 5\% and $8 \%$ concentration of sodium hydroxide have been used to treat bamboo and sisal fibers respectively to eliminate lignin, cellulose, and other dirty particles in order to increase interfacial bonding of epoxy to fibers, and performance of the composite. Taguchi experimental approach is used to design composite by considering basic parameters such as weight fraction of sisal, fibers orientation, and curing temperature which affect composite performance. Compression molding and hand lay-up techniques have been used to fabricate the composite. The compression and hardness tests ware predicted on the specimen of hybrid bamboo/sisal fiber reinforced epoxy composites prepared with ASTM standard. The analyzed result revealed that the composite contains a $20 / 15 \%$ volume fraction of sisal to bamboo fibers and fabricated with fiber plies orientation of $\left[0_{\mathrm{S}} / 0_{\mathrm{B}} / 0_{\mathrm{S}} / 0_{\mathrm{B}} / 0_{\mathrm{S}} / 0_{\mathrm{B}}\right]$ and curing temperature at $40^{\circ} \mathrm{C}$ record a high compression strength. While the better hardness strength obtained from composite contain $15 / 20 \%$ volume fraction of sisal to bamboo fibers, and fabricated with fiber plies orientation of $\left[0_{\mathrm{S}} / 0_{\mathrm{B}} / 0_{\mathrm{S}} / 0_{\mathrm{B}} / 0_{\mathrm{S}} / 0_{\mathrm{B}}\right]$ and cured at $55^{\circ} \mathrm{C}$.
\end{abstract}

Keywords: bamboo/sisal fibers, compression \& hardness strength, taguchi method
Volume 5 Issue 2 - 2021

\author{
Sheleme Mosisa,' Temesgen Batu² \\ 'Department of Mechanical and Chemical Engineering,Wollo \\ University, Ethiopia \\ ${ }^{2}$ University of Stavanger, Norway
}

Correspondence: Sheleme Mosisa, Department of Mechanical and Chemical Engineering, Kombolcha Institute of Technology, Wollo University, P.O. Box. I I45, Ethiopia, Tel +25 I922484024, Emailshelemmemosisa@gmail.com

Received: February 25, 2020 | Published: March 24, 2021

\section{Introduction}

In recent Decades, synthetic fiber-reinforced polymers matrix composite materials are preferred in different industrial and structural applications due to they have lightweight, high stiffness, and the ratio of specific strength to weight. ${ }^{1}$ However, they have disadvantages such as high production cost, environmental effect during the production period and they do not recycle waste after use. Recently, researchers focus on natural fibers reinforcement in place of synthetic fibers to prepare environmental friendly composite materials. ${ }^{2}$ The natural fibers specifically, Bamboo, Sisal, Banana, Jute Flax, kenaf and other natural fibers are inherently lightweight low cost, environmentally friendly, and low density. Using natural fiber reinforced polymers composite as an alternative to synthetic fibers reinforced polymers have been started in recent last years. But still, the mechanical strength of the natural fiber-based composite was lagging behind to synthetic fiber-based composite. For this reason, most researchers ${ }^{3,4}$ did various studies by considering fibers type, hybridizing fibers, stacking orientation of fibers, the geometry of fibers, fabricating technique, matrix type and by treating the surface of fibers to increase the performance of natural fiber reinforced polymer composite materials. K.V. Sreenivas Rao, et al. studied on the mechanical property of Hybrid (sisal-flax, sisal-hem, and sisal-coir) fibers reinforced epoxy composites. The fibers are treated with $\mathrm{NaOH}$ and the hand lay-up method ware used to fabricate all composites. The investigated experimental result display, that the large compression and hardness strength recorded for hybrid sisal-coir reinforced epoxy composite. ${ }^{3}$ Navjot PS, the mechanical property of hybrid sisal/hemp fiber reinforced HDPE composite is superior to single fiber-reinforced composite. ${ }^{4}$ Also, S. A. H. Roslan, et al, revised the characterized mechanical properties of various bamboo fiber structure and various polymers to develop composite materials. Ashwin Sailesh et al. ${ }^{5}$ studied on determination of the best hardness values for hybrid banana-bamboo-chopped strand glass fibers reinforced epoxy resin composites. the composite were designed according to Taguchi $\mathrm{L}_{4}$ orthogonal arrays depending on three factors (orientation of plies, matrix/hardness ratio and curing time) with two levels and fabricated with hand layup technique. The analyzed SN ratio display that the hybrid (bamboobanana-chopped strand glass) fibers reinforced epoxy composites designed with plies orientation $\left[0_{\mathrm{G}}, 0_{\mathrm{BM}},+45_{\mathrm{BN}}, 0_{\mathrm{G}}\right]$, epoxy to hardness ratio $(10: 1)$ and 30 minutes curing time gave the better hardness values. ${ }^{5}$ Generally, this work concludes that the appropriate hardness of composite material is found by properly design the orientation of fibers and matrix to hardener mixing ratios.

From Natural fibers, The Sisal and Bamboo fibers are great attention of most researchers' due to they are advantageous over synthetic fibers. Both Sisal and Bamboo fibers are extracted chemically, mechanically, or by combining both processes from sisal (Agave sisalana) and bamboo plants respectively. ${ }^{6}$ The mechanical properties of bamboo fibers are near to glass fibers. But the factors such as fiber orientation, bamboo species and age, fiber length and amount of treatment influence the mechanical strength of bamboo fiber. ${ }^{6,7}$ The sisal fibers have cultivated in countries like East Africa, Haiti, Brazil, India, and Indonesia. ${ }^{8}$ While Bamboo plants Asia-Pacific(India, China, Burma, Malaysia, etc), Africa (Mozambique, Ethiopia, Eastern Sudan, etc), America (Mexico, Columbia, Brazil, Costa Rica, etc) and Europe (England, France, Germany, Italy, etc). Both Sisal and bamboo fibers are inherently combined with cellulose and lignin materials. These materials have the ability to absorb the moisture and decreases interbonding of fibers with a matrix which is the root cause of decrease the mechanical strength of the composite. To eliminate this cause, various researchers use varies alkali and acid in chemicals to treat the surface of fibers in order to improve interface bonding of matrix and fibers. ${ }^{89} \mathrm{NaOH}$ is the common alkali chemicals which various studs have been used with different concentration. Hence this work was conducted to investigate the compression and hardness tests and analyze the strength on the specimen of various composite made of 
hybrid bamboo-sisal fibers as a reinforcement with epoxy resin as matrix fabricated by hand layup and compression mold.

\section{Materials and experimental methods}

\section{Materials}

In this experiment, epoxy resin and catalyst (hardener) with a brand name ("SYSTEM \# 2000 EPOXY") and ("SYSTEM \# 2060 HARDENER"), respectively are purchased from KADISCO paint industry Town Addis Ababa, Ethiopia which is manufactured with fiber Glast development Corporation Company was used. Reinforcement is the basic element in composite materials to increase the strength and stiffness. For this Experimental investigation, bamboo and sisal fibers are mechanically \& manually extracted from three years of age of bamboo plant culms (Dendrocalamus asper) bamboo species and six years age of sisal plant(Agave sisalana) respectively in African bamboo P.L.C. Addis Ababa, Ethiopia. Both sisal and bamboo plants are demographically obtained from zone west shewa town Ambo, Ethiopia.

\section{Extraction process and treatment of fibers}

Firstly, the bamboo culms with around $180 \mathrm{~cm}$ long are divided into four slabs by using a circular hack-saw machine. All slabs are banded and crushed by using circular banding and crushing machines respectively to remove liquid forms and the thinner layer exoderm from the inner bamboo Culm. Three weeks have been used to dry the crushed bamboo culms in the sun. Secondly, the dried bamboo strips are waiting in the water for twelve hours in order to make a soften slab. Then the bamboo strips are manually beaten many times at a slow uniform impact load using a rubber hammer in order to get single fiber. The resulting fiber bundle is combed using a steel wire comb. The process of beating and combing is repeated until individual fibers are separated. The strongest part of six years age of sisal plant leaf had cut out from the original sisal plant. Both ends of sisal plants have been trimmed to get the appropriate size. The surface of the sisal leave is scrapped by a sharp knife with the guidance of a wood table up to get the single fiber. The mixture of fibers and cellulose have been washed in pure water to identify the single fibers. Finally, the sisal fibers have been dried for 60 hours in the sun. The bamboo and sisal fibers have been treated in $5 \%$ and $8 \%$ concentration of $\mathrm{NaOH}$ for 4 and 8 hours respectively. Then, the fiber washed many times with fresh water in order to reduce reactivity with the environment. Finally, these fibers dried in sunlight for 48 hours.

\section{Experimental design method}

The composite contents and the fabrication process are the basic influence the mechanical properties of composites materials. Hence, the experimental study has been performed on the hybrid sisal-bamboo fibers reinforced composite fabricated with various fibers stacking orientation, various fibers content and curing temperature. The details of considered parameters, which influence the Compression and Hardness strength, have been presented in Table 1.

Table I The levels and values of factors which affect the compression and hardness strength

\begin{tabular}{llll}
\hline \multirow{2}{*}{$\begin{array}{l}\text { Factors affect composite } \\
\text { properties }\end{array}$} & \multicolumn{2}{l}{ Levels of factors and values } \\
\cline { 2 - 4 } & Level I & Level 2 & Level 3 \\
\hline Sisal fiber (wt \%) & 25 & 20 & 15 \\
Bamboo fiber (wt \%) & 25 & 20 & 15 \\
Plies orientation $\left({ }^{\circ}\right)$ & {$[0 / 0 / 0 / 0 / 0 / 0]$} & {$[90 / 90 / 90 / 90 / 90 / 90]$} & {$[0 / 90 / 90 / 0 / 0 / 90]$} \\
Curing temperature $\left(C^{\circ}\right)$ & 25 & 40 & 55 \\
\hline
\end{tabular}

\section{Taguchi design of experiment}

Taguchi experimental design approach is the appropriate technique as it is used for various product quality control, process optimization, and product development and uses the minimum number of runs. It is a group of fractional factorial designs depend on the estimation of the main effect. For this study, four factors and three runs (levels) for each factor were considered for composite preparation

The Taguchi experimental design steps are described as follows: ${ }^{10}$

I. Identify the problem and noise factors

II. Determine design parameters that influence product strength.

III. Determine control parameters with their levels response

IV. Chose the appropriate orthogonal array

V. Conduct experiments.

VI. Analysis final result and summarize the effect of factors

Identify the problem and noise factors: To determine the influence of fiber's values and fabrication process on the Compression and Hardness strength of Hybrid Bamboo/sisal fibers reinforced epoxy composite materials.
Determine design parameters which influence product strength: The fibers weight percentage; fiber orientation and socking temperature during compression molding are considered as design factors that influence the performance of composite material.

Determine control parameters with their levels response: The Compression and hardness strength are chosen as a response variable for the investigation. Control parameters are the variables that influence the result of the process or the product. The factors listed in Table 1 were chosen as control parameters with their levels.

Chose the appropriate orthogonal array: Taguchi representation for the orthogonal arrays is; $\mathrm{La}\left(\mathrm{b}^{\wedge} \mathrm{c}\right)$, where $\mathrm{a}$ is the value experimental runs, $b$ is the value of levels for each factor, and $c$ is the value of variables. Several levels of factors are used in orthogonal arrays. In this investigation, the factors are listed with their levels in Table 2 depending on L9 orthogonal arrays.

\section{Preparation of composite sample preparation and mechanical property characterization}

For this study, nine types of the composite are fabricated by hand layup process and compression molding technique with pre-designed curing temperature. There are six plies of fibers are combined to 
make each composite. The 2:1 Epoxy resin to hardener chemicals ware mixed well and painted on the surface of the plies layer by layer to adhesive the fibers. At first, the aluminum foam was placed over the wide steel plate to make a good and clean surface finish of the composite. Then the wax painted on the surface of aluminum foam used for simply releasing at the end of curing time. After that, the epoxy resin spread on the painted wax. The fibers are over placed one by one and painted up to the last layer. Then the prepared samples were allowed to compress with the $5 \mathrm{Mpa}$ pressure Compression machine (Figure 1).

Table 2 Orthogonal arrays for the design of the experiment

\begin{tabular}{lllll}
\hline $\begin{array}{l}\text { Types of } \\
\text { composite }\end{array}$ & Sisal mass fraction (\%) & $\begin{array}{l}\text { Bamboo mass } \\
\text { fraction }(\%)\end{array}$ & The orientation of fiber plies & $\begin{array}{l}\text { The curing } \\
\text { temperature }\left(C^{\circ}\right)\end{array}$ \\
\hline BSFRPHC I & 25 & 25 & {$\left[0_{\mathrm{S}} / 0_{\mathrm{B}} / 0_{\mathrm{S}} / 0_{\mathrm{B}} / 0_{\mathrm{S}} / 0_{\mathrm{B}}\right]$} & 25 \\
BSFRPHC 2 & 25 & 20 & {$\left[90_{\mathrm{B}} / 90_{\mathrm{S}} / 90_{\mathrm{B}} / 90_{\mathrm{S}} / 90_{\mathrm{B}} / 90_{\mathrm{S}}\right]$} & 40 \\
BSFRPHC 3 & 25 & 15 & {$\left[0_{\mathrm{S}} / 90_{\mathrm{B}} / 90_{\mathrm{S}} / 0_{\mathrm{B}} / 0_{\mathrm{S}} / 90_{\mathrm{B}}\right]$} & 55 \\
BSFRPHC 4 & 20 & 25 & {$\left[90_{\mathrm{B}} / 90_{\mathrm{S}} / 90_{\mathrm{B}} / 90_{\mathrm{S}} / 90_{\mathrm{B}} / 90_{\mathrm{S}}\right]$} & 55 \\
BSFRPHC 5 & 20 & 20 & {$\left[0_{\mathrm{S}} / 90_{\mathrm{B}} / 90_{\mathrm{S}} / 0_{\mathrm{B}} / 0_{\mathrm{S}} / 90_{\mathrm{B}}\right]$} & 25 \\
BSFRPHC 6 & 20 & 15 & {$\left[0_{\mathrm{S}} / 0_{\mathrm{B}} / 0_{\mathrm{S}} / 0_{\mathrm{B}} / 0_{\mathrm{S}} / 0_{\mathrm{B}}\right]$} & 40 \\
BSFRPHC 7 & 15 & 25 & {$\left[0_{\mathrm{S}} / 90_{\mathrm{B}} / 90_{\mathrm{S}} / 0_{\mathrm{B}} / 0_{\mathrm{S}} / 90_{\mathrm{B}}\right]$} & 40 \\
BSFRPHC 8 & 15 & 20 & {$\left[0_{\mathrm{S}} / 0_{\mathrm{B}} / 0_{\mathrm{S}} / 0_{\mathrm{B}} / 0_{\mathrm{S}} / 0_{\mathrm{B}}\right]$} & 55 \\
BSFRPHC 9 & 15 & 15 & {$\left[90_{\mathrm{B}} / 90_{\mathrm{S}} / 90_{\mathrm{B}} / 90_{\mathrm{S}} / 90_{\mathrm{B}} / 90_{\mathrm{S}}\right]$} & 25 \\
\hline
\end{tabular}

Note: BSFRPHC with stand bamboo-sisal fibers reinforced polymer hybrid composite

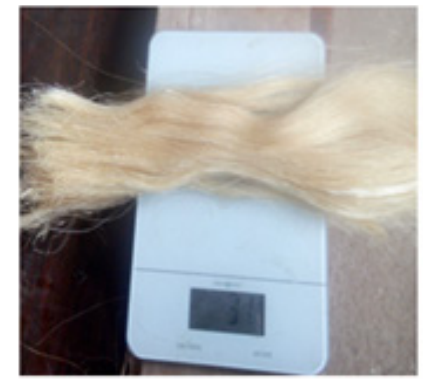

(a)

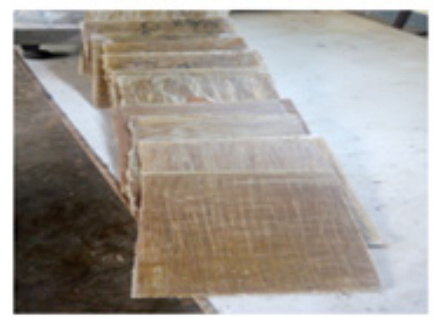

(d)

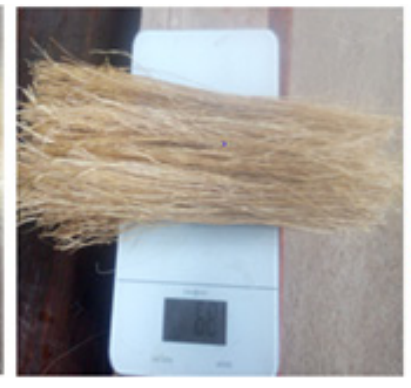

(b)

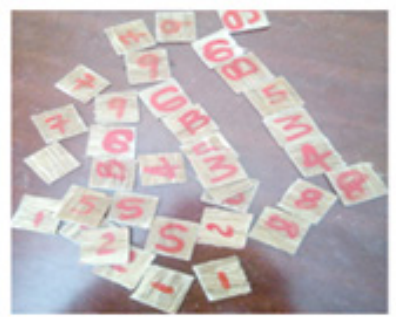

(e)

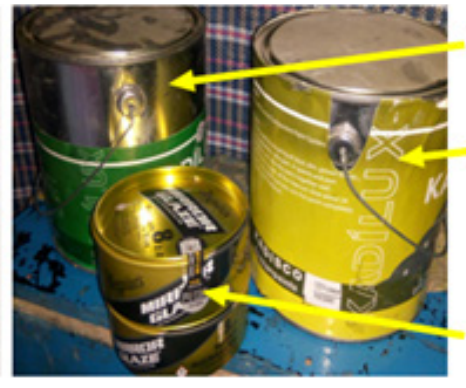

Epoxy

Hardener

(c)

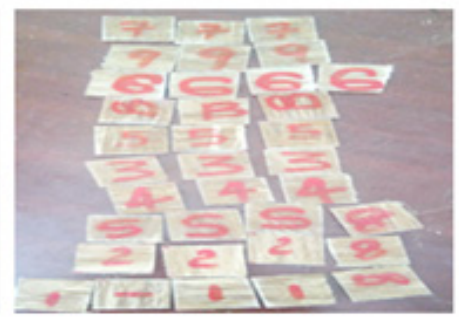

(f)

Figure I Materials and prepared samples for compression and hardness test (A) sisal fiber, (B) bamboo fiber, (C) epoxy, hardener and wax, (D) prepared composites, (E) specimen for hardness test, $(F)$ prepared specimen for compression test.

Compression test: The compression strength testing was performed on hybrid Bamboo/Sisal fiber reinforced epoxy composite in a laboratory experiment. In this section, the prepared specimen was involved in axial compression loading using the UTM. The dimension of the specimen is $(25 \times 25 \times 3.17)$ which is prepared according to ASTM D3410. To obtain the result of the compression test, the specimen is inserted into the test fixture which is placed between the plates of the testing machine and loaded in compression. The maximum load attained was recorded by the UTM testing system after the specimen failed. A typical specimen failure is shown in Figure 2.
Hardness test: The hardness testing was performed on hybrid sisal/bamboo fibers reinforced epoxy composite in a laboratory experiment. In this section, the prepared specimen was involved in hardness testing using the Rockwell Hardness testing machine as per scale -A. The dimension of the specimen is $(20 \times 20 \times 3) \mathrm{mm}^{3}$ were prepared as per ASTM D 384. To obtain Hardness test results, the specimen is inserted into the test fixture which is placed between the bottom circular plates of the testing machine and upper $60 \mathrm{~kg}$ loaded in according to scale $-\mathrm{A}$. after $60 \mathrm{~kg}$ load attained by hand control loading part, the hardiness values recorded on the dial. The hardness testing fixture is shown in Figure 3. 


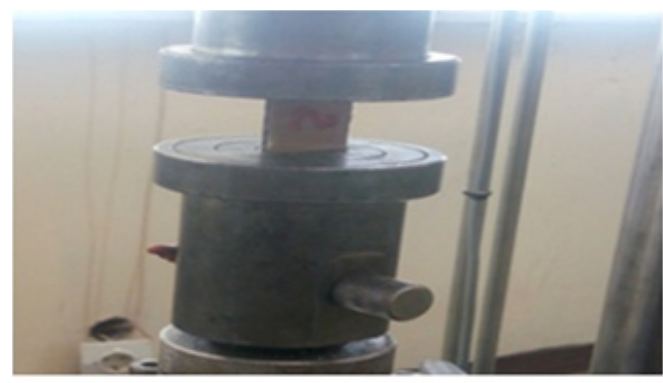

(a)

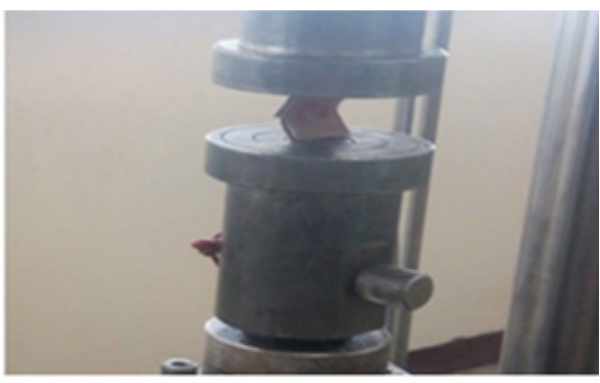

(b)

Figure 2 (A) Fixture of compression test and (B) Failure mode of samples after the test.

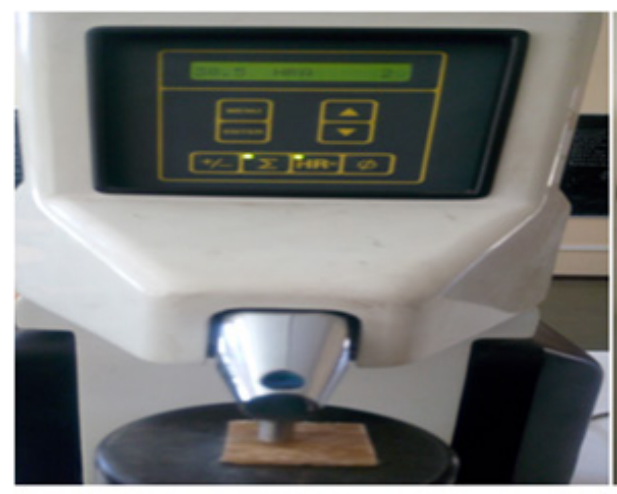

(a)

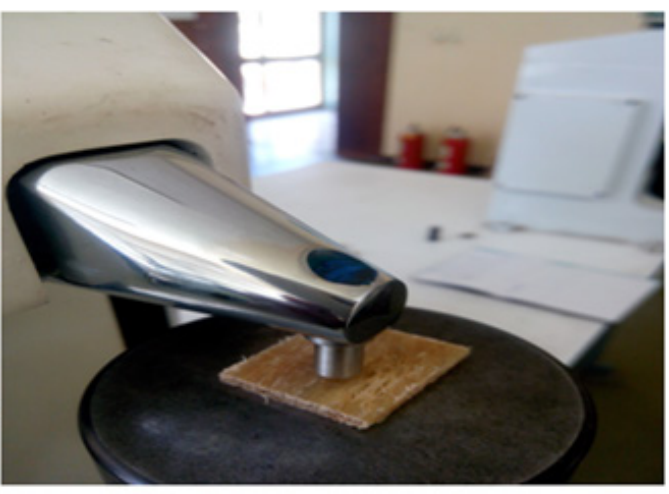

(b)

Figure 3 (A) The front view of the hardness test Fixture, (B) Side view of the hardness test fixture.

\section{Result and discussion}

\section{Evaluation of compression strength}

The compressive strength has been evaluated for nine different types of hybrid sisal bamboo fibers reinforced epoxy composite. For each composite, five similar specimens are prepared and tested. Figure 4 displays the average values of stress-strain curves of compression strength for all composites obtain during the compression test. The graph indicates nonlinear segments (there is up and down) and the curve is not smooth, in which the jerky/stick-slip behavior is responsible for this response. During fracture compressive stress of BSFRPHC rapidly decreased with buckling of the specimen.
The weight percentage of fibers, fiber plies orientation and curing temperature plays a great influence on the compression strength of the composite. For example from Figure 5 the composite type BSFRPHC 6 is fabricated with $(25 / 15$ wt. \% sisal to bamboo fibers, $60 \%$ epoxy), fibers stack-oriented $\left[0_{\mathrm{S}} / 0_{\mathrm{B}} / 0_{\mathrm{S}} / 0_{\mathrm{B}} / 0_{\mathrm{S}} / 0_{\mathrm{B}}\right]$ and composite cured with $40^{\circ} \mathrm{C}$ has given large ultimate compressive strength (47.44Mpa) while BSFRPHC 2 which fabricated with 25/20\%sisal /bamboo volume percentage, fiber orientation $\left[90_{\mathrm{B}} / 90_{\mathrm{S}} / 90_{\mathrm{B}} / 90_{\mathrm{S}} / 90_{\mathrm{B}} / 90_{\mathrm{S}}\right]$ and at $40^{\circ} \mathrm{C}$ curing temperature had record lower ultimate compression strength $(8.79 \mathrm{Mpa})$. From this increasing sisal fiber volume fraction, increase compression strength. The orientation of fiber also plays a vital role to increase the compression strength.

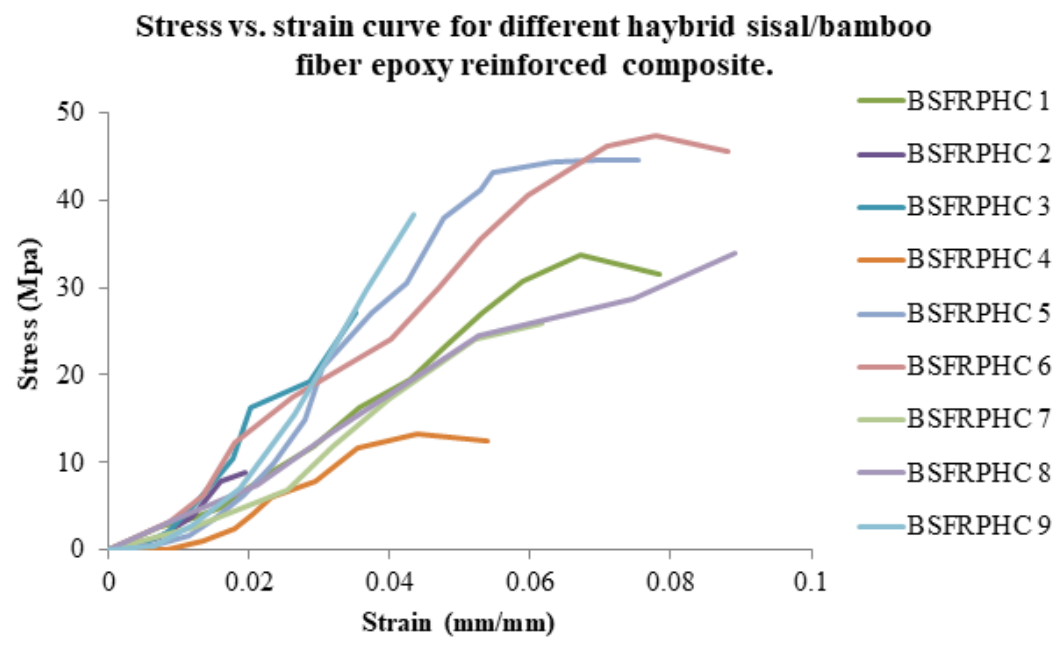

Figure 4 The average value of the stress-strain curve for the compression test. 


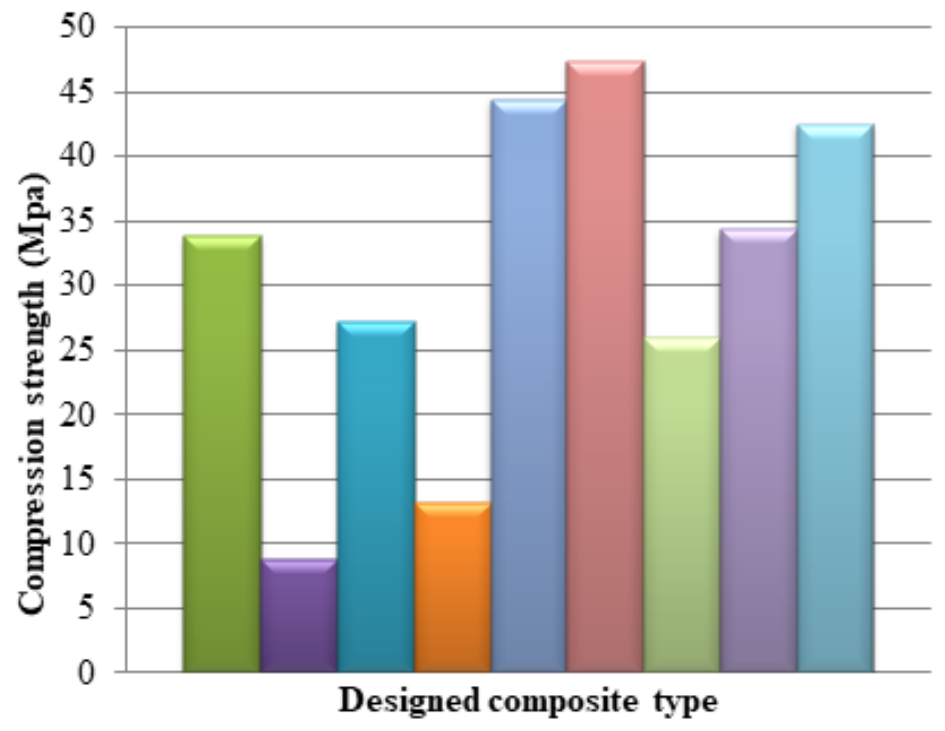

\section{$\square$ BSFRPHC 1}

$\triangle \mathrm{BSFRPHC} 2$

$\square$ BSFRPHC 3

$\square \mathrm{BSFRPHC} 4$

$\triangle \mathrm{BSFRPHC} 5$

$\square$ BSFRPHC 6

$\square$ BSFRPHC 7

$\square$ BSFRPHC 8

$\square$ BSFRPHC 9

Figure 5 The average value of compression strength of all BSFRPHC.

\section{Evaluation of hardness strength}

It is seen that from table Table 3, the BSFRPHC 1have low hardness number (2.18 HRA). From these values, we observe that the inter bonding of hybrid sisal/bamboo fiber reinforced epoxy composite is low due to this composite is fabricated at $25^{\circ} \mathrm{C}$. The hardness number increase due to increasing curing temperature and decreasing bamboo fiber volume fraction. The BSFRPHC (8\&9) are fabricated from the same bamboo fiber volume matrix $(15 \%)$ but the hardness number of BSFRPHC 9 (8HRA) is lower than BSFRPHC 8(23.4 HRA).from this we conclude that the hardness number of BSFRPHC increase for $55^{\circ} \mathrm{C}$ curing temperature, $\left[0_{\mathrm{S}} / 0_{\mathrm{B}} / 0_{\mathrm{S}} / 0_{\mathrm{B}} / 0_{\mathrm{S}} / 0_{\mathrm{B}}\right]$ orientation of fiber and $15 \% / 20 \%$ sisal/ bamboo fiber volume fraction content (Figure 6). Now, we have to find the ratio of Signal to Noise for all data of compression and hardness strength tabulated in Table 4 . The three functions have been postulated by Taguchi are:

1. Smaller the better

2. Larger the better

3. Nominal the best

Table 3 Hardness test result

\begin{tabular}{lllllll}
\hline \multirow{2}{*}{ Composite type } & \multicolumn{7}{l}{ Hardness number in HRA } & & & \\
\cline { 2 - 6 } & Samples I & Samples 2 & Samples 3 & Samples 4 & Samples 5 & Average sample \\
\hline BSFRPHC I & 2.9 & 3.2 & 1.8 & 1.4 & 1.6 & 2.18 \\
BSFRPHC 2 & 1.7 & 2.5 & 4.4 & 1.5 & 3.2 & 2.66 \\
BSFRPHC 3 & 13.4 & 16.7 & 14.9 & 17.4 & 14.2 & 15.32 \\
BSFRPHC 4 & 12.3 & 12.1 & 9 & 11.8 & 10.2 & 11.08 \\
BSFRPHC 5 & 15 & 23.4 & 21.1 & 29.6 & 16 & 21.02 \\
BSFRPHC 6 & 13.4 & 13.3 & 14.7 & 12.8 & 25.6 & 15.96 \\
BSFRPHC 7 & 16.2 & 18.2 & 21.4 & 22.5 & 25.2 & 20.7 \\
BSFRPHC 8 & 14.2 & 17.7 & 25 & 29.4 & 33.4 & 23.94 \\
BSFRPHC 9 & 3.2 & 5 & 5.6 & 7.7 & 18.5 & 8 \\
\hline
\end{tabular}

Table $4 \mathrm{~S} / \mathrm{N}$ ratios values for ultimate compression and hardness strength

\begin{tabular}{lllll}
\hline Composite type & $\begin{array}{l}\text { Compression } \\
\text { strength (Mpa) }\end{array}$ & $\begin{array}{l}\text { S/N ratio values for } \\
\text { compression strength }\end{array}$ & $\begin{array}{l}\text { The average value of } \\
\text { hardness number in HRA }\end{array}$ & $\begin{array}{l}\text { S/N ratio values for } \\
\text { hardness strength }\end{array}$ \\
\hline BSFRPHC I & 33.81 & 30.45 & 27.78 & 6.77 \\
BSFRPHC 2 & 8.79 & 18.87 & 4.04 & 8.49 \\
BSFRPHC 3 & 27.19 & 28.68 & 2.18 & 23.7 \\
BSFRPHC 4 & 13.24 & 22.43 & 2.66 & 20.89 \\
BSFRPHC 5 & 44.62 & 32.99 & 15.32 & 26.45 \\
\hline
\end{tabular}




\begin{tabular}{lllll} 
Table Continued... & \multicolumn{1}{l}{$\begin{array}{l}\text { Compression } \\
\text { Composite type }\end{array}$} & $\begin{array}{l}\text { S/N ratio values for } \\
\text { strength (Mpa) } \\
\text { compression strength }\end{array}$ & $\begin{array}{l}\text { The average value of } \\
\text { hardness number in HRA }\end{array}$ & $\begin{array}{l}\text { S/N ratio values for } \\
\text { hardness strength }\end{array}$ \\
\hline BSFRPHC 6 & 47.44 & 33.52 & 11.08 & 24.06 \\
BSFRPHC 7 & 25.99 & 28.29 & 21.02 & 26.32 \\
BSFRPHC 8 & 33.31 & 30.45 & 15.96 & 27.58 \\
BSFRPHC 9 & 42.48 & 32.56 & 20.7 & 18.06
\end{tabular}

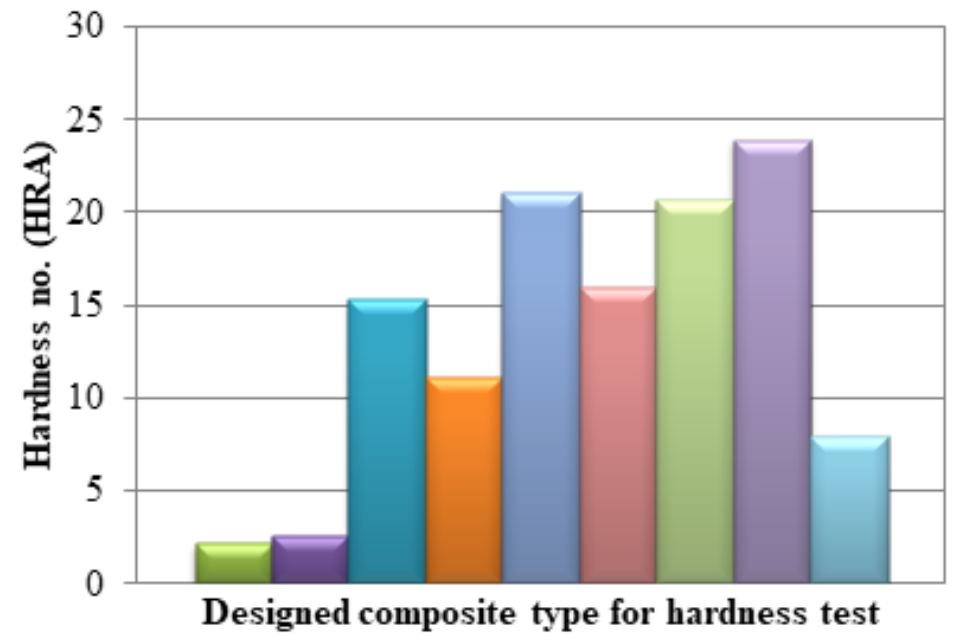

$\square$ BSFRPHC 1

$\square$ BSFRPHC 2

$\square$ BSFRPHC 3

$\square$ BSFRPHC 4

$\square$ BSFRPHC 5

$\square$ BSFRPHC 6

$\triangle \mathrm{BSFRPHC} 7$

$\square$ BSFRPHC 8

$\triangle \mathrm{BSFRPHC} 9$

Figure 6 The average value of hardness strength of all BSFRPHC.

In this experimental, the larger better is selected to determine the compression and hardness performance of prepared composite specimens. According to the Taguchi design approach, the ratio of product quality (signal) to uncontrollable factors (noise) should be high. The signal to noise $(\mathrm{S} / \mathrm{N})$ ratio for large better types of the objective function is calculated as follows:

$\eta=-10 \log _{10} \frac{1}{y^{2}}$ Where $-\mathrm{y}$ is the value of ultimate strength.

The $\mathrm{S} / \mathrm{N}$ ratio values for each experiment are computed by using the MINITAB version 18.0 software. The computed $\mathrm{S} / \mathrm{N}$ ratio from MINITAB software is presented in Table $4 \&$ Table 5. From Figure $7 \mathrm{~A} \& \mathrm{7B}$, it is seen that a large $\mathrm{SN}$ ratio was recorded for sisal and bamboo fibers of volume fraction at level $3(15 \%$ and $15 \%)$ respectively. and also from Figure 7C \& 7D observed that the large
SN ratio was seen for fiber orientation and curing temperature at level $1\left[0_{\mathrm{S}} / 0_{\mathrm{B}} / 0_{\mathrm{S}} / 0_{\mathrm{B}} / 0_{\mathrm{S}} / 0_{\mathrm{B}}\right]$ and level $1\left(25^{\circ} \mathrm{C}\right)$ respectively. Generally to increase the compression strength of hybrid sisal/bamboo fiber reinforced epoxy composite under a compression load, fabricate hybrid sisal/bamboo with fiber volume fraction $(15 \% / 15 \%)$, sisal/ bamboo fiber orientation $\left[0_{\mathrm{S}} / 0_{\mathrm{B}} / 0_{\mathrm{S}} / 0_{\mathrm{B}} / 0_{\mathrm{S}} / 0_{\mathrm{B}}\right]$ and curing at $25^{\circ} \mathrm{C}$ room temperature is the best one. Figure $8 \mathrm{~A} \& 8 \mathrm{~B}$, explain that large $\mathrm{SN}$ ratio was recorded for sisal and bamboo fibers of volume fraction at level $3(15 \%$ and $15 \%)$ respectively. and also the Figure $8 \mathrm{C} \& 8 \mathrm{D}$, we observe that the large $\mathrm{SN}$ ratio was seen for fiber orientation and curing temperature at level $3\left[0_{\mathrm{S}} / 90_{\mathrm{B}} / 90_{\mathrm{S}} / 0_{\mathrm{B}} / 0_{\mathrm{S}} / 90_{\mathrm{B}}\right]$ and level $3\left(55^{\circ} \mathrm{C}\right)$ respectively. From this result, the hardness strength increase due to the sisal and bamboo fiber weight decrease from $25 \%$ to $15 \%$ and due to increasing temperature from $25^{\circ} \mathrm{C}$ to $55^{\circ} \mathrm{C}$. And also bi-unidirectional fiber orientation increase hardness strength.

Table 5 The response values of the control factors at each level for both ultimate compression \& hardness strength

\begin{tabular}{lllllll}
\hline Factors & & Level I & Level 2 & Level 3 & Max-Min & Rank \\
\hline $\begin{array}{l}\text { Sisal } \\
\text { mass fraction \% }\end{array}$ & For compression & 26 & 29.64 & 30.43 & 4.43 & 4 \\
& For hardness & 12.98 & 23.8 & 23.98 & II & I \\
Bamboo mass fraction \% & For compression & 27.05 & 27.43 & 31.58 & 4.53 & 3 \\
& For hardness & 17.99 & 20.84 & 21.94 & 3.95 & 4 \\
Fiber orientation & For compression & 31.47 & 24.62 & 29.98 & 6.85 & 1 \\
& For hardness & 19.47 & 15.81 & 25.49 & 9.68 & 2 \\
Curing temperature & For compression & 32 & 26.89 & 27.18 & 5.11 & 2 \\
\hline
\end{tabular}



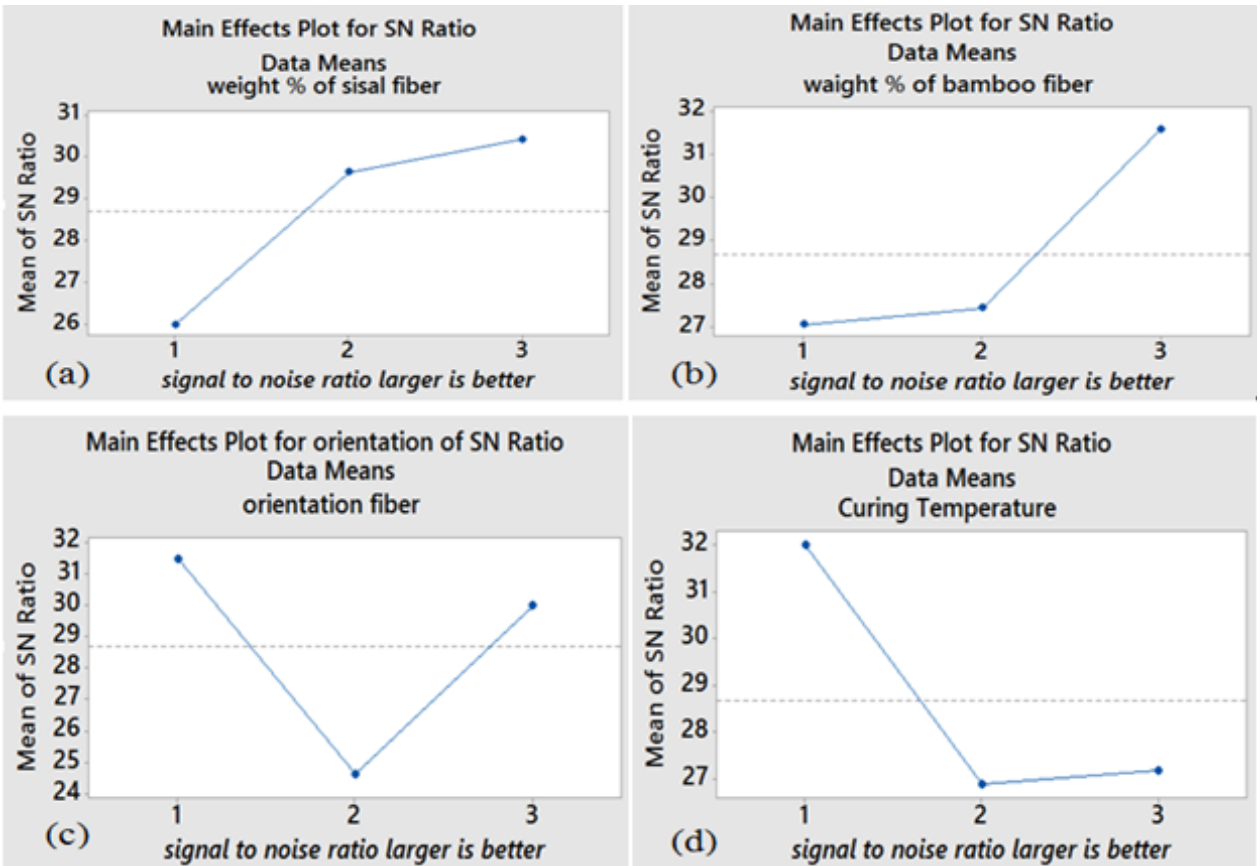

Figure 7 Mean effects plot for $\mathrm{S} / \mathrm{N}$ ratios under compression strength.
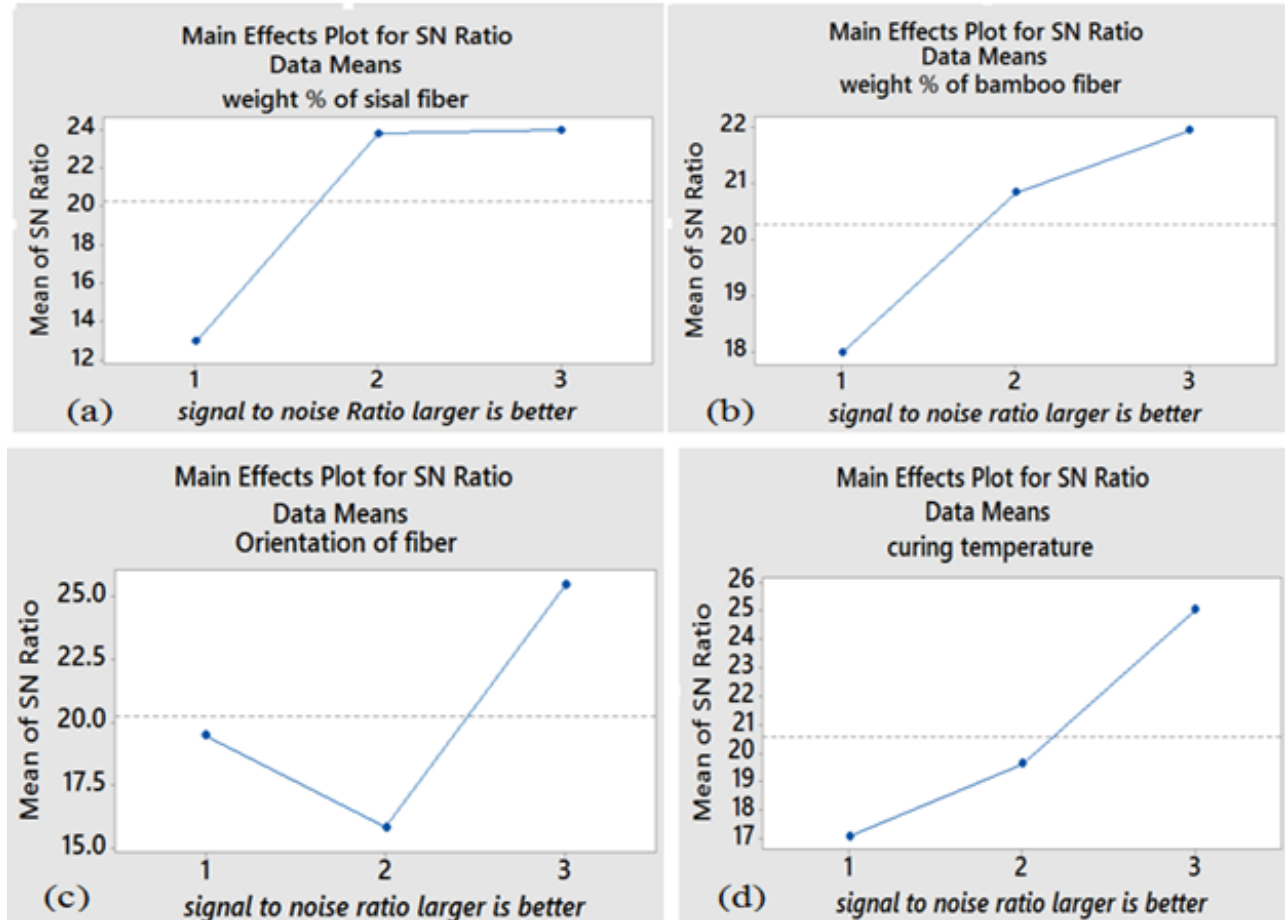

Figure 8 Main effects plot for SN ratios for hardness test.

\section{Conclusions}

In this study, bamboo and sisal fibers are extracted manually and mechanically from bamboo and sisal plants respectively. Alkaline treatment was carried out for both sisal and bamboo $8 \%$ and 5\% $\mathrm{NaOH}$ concentration respectively to remove cellulose, lignin, and other fats. Next to that the sisal/bamboo fibers reinforced epoxy hybridized composite material was fabricated and characterized the mechanical properties specifically compression and hardness strength by using laboratory tests. Based on the result data obtained from

experimentally investigated compression and hardness tests, few points described as follows:

a) The sisal/Bamboo fibers reinforced epoxy matrix hybrid composite material fabricated at $40^{\circ} \mathrm{C}$ Consolidation temperature with $20 / 15 \%$ sisal to bamboo fibers, $65 \%$ epoxy volume fraction and oriented fibers with $\left[0_{\mathrm{S}} / 0_{\mathrm{B}} / 0_{\mathrm{S}} / 0_{\mathrm{B}} / 0_{\mathrm{S}} / 0_{\mathrm{B}}\right]$ record the maximum values of compression strength (47.44Mpa).

b) While the composite fabricated with $55^{\circ} \mathrm{C}$ Consolidation temperature with $15 / 20 \%$ sisal to bamboo fibers, $65 \%$ epoxy 
volume fraction and oriented fibers with $\left[0_{\mathrm{S}} / 0_{\mathrm{B}} / 0_{\mathrm{S}} / 0_{\mathrm{B}} / 0_{\mathrm{S}} / 0_{\mathrm{B}}\right]$ record the maximum values of hardness strength (23.4 HRA).

c) The result observed from $\mathrm{S} / \mathrm{N}$ curve reveals that fibers stack $\left[0_{\mathrm{S}} / 0_{\mathrm{B}} / 0_{\mathrm{S}} / 0_{\mathrm{B}} / 0_{\mathrm{S}} / 0_{\mathrm{B}}\right]$ and curing temperature $\left(25^{\circ} \mathrm{C}\right)$ have played a great role to increase compression strength. For hardness strength, the $\mathrm{S} / \mathrm{N}$ curve shows fiber orientation level $3\left[0_{\mathrm{S}} / 90_{\mathrm{B}} / 90_{\mathrm{S}} / 0_{\mathrm{B}} / 0_{\mathrm{S}} / 90_{\mathrm{B}}\right]$ and curing temperature at level $3\left(55 \mathrm{c}^{\circ}\right)$ is the better. For both compression and hardness investigation, the $\mathrm{S} / \mathrm{N}$ curve ensures that the strength increase due to a decrease in the sisal and bamboo volume fraction decrease from $25 \%$ to $15 \%$.

d) From the experimental investigation and characterization result, henceforth, can generalize that the hybrid bamboo/ sisal fiber reinforced epoxy matrix composite material has significantly good mechanical strength, along with the inherent importance being cost-effectiveness, environmentally friendly, low specific to weight ratio and so on for various application.

\section{Acknowledgments}

The support of African Bamboo PLC on composite sample preparation and Bishoftu Defense College material testing laboratory with composite sample testing are highly appreciated.

\section{Conflicts of interest}

The authors declare that there is no conflict of interest regarding the publication of this article.

\section{References}

1. Ma ML, Wang GL. Frp Structure Design Method Based On The Stiffness Equivalence: Case Study And Practice. Engineering Review. 2012;32(3):165-171.
2. Santulli C, Sarasin F, De Rosa Igor Maria, et al. Mechanical and thermal characterization of epoxy composites reinforced with random and quasiunidirectional untreated Phormium Tenax leaf fibers. Materials \& Design (1980-2015). 2010;31(5):2397-2405.

3. Sreenivas Rao KV, Akash NSVG, Sanjeevamurthy. Mechanical Properties Of Natural Fibers Reinforced Hybrid Composites. ARPN Journal of Engineering and Applied Sciences. 2016;11(1).

4. Singh NP, Aggarwal L, Gupta VK. Tensile Behavior of Sisal/Hemp Reinforced High-Density Polyethylene Hybrid Composite. Materials Today: Proceedings. 2015;2(4-5):3140-3148.

5. Ashwin Sailesh CS. Predicting the best hardness of Banana-BambooGlass fiber-reinforced Natural fiber composites using Taguchi method. International Journal of Engineering Development and Research. 2018.

6. Abdul Khalil HPS, Bhat IUH, Jawaid M, et al. Bamboo fiber-reinforced biocomposites: A review. Materials \& Design. 2012;42:353-368.

7. Mohammed L. A Review on Natural Fiber Reinforced Polymer Composite and Its Applications. International Journal of Polymer Science. 2015:115 .

8. Kuruvilla Joseph RDTF, Beena James, Sabu Thomas, et al. A Review On Sisal Fiber Reinforced Polymer Composites. Revista Brasileira de Engenharia Agrícola e Ambiental. 1999;3(3):367-379.

9. Girisha CS, Gunti Rangasrinivas, Manu S, et al. Mechanical Performance Of Natural Fiber-Reinforced Epoxy-Hybrid Composites. International Journal of Engineering Research and Applications. 2012;2(5).

10. Sorana D, Bolboacă ALJ. Design of Experiments: Useful Orthogonal Arrays for Number of Experiments from 4 to 16. Entropy. 2007;9:198232. 